\title{
Pandemia e hiper-realidade: o fim sem fim do Ocidente em um confronto a partir de Heidegger e Baudrillard
}

\section{Pandemic and hyper-reality: the endless end of the West in a confrontation between Heidegger and Baudrillard}

\section{Paulo Victor Rodrigues da Costa ${ }^{1}$ \\ Universidade do Estado do Rio de Janeiro \\ pvrcosta@gmail.com \\ http://orcid.org/0000-0002-4883-0295}

\section{RESUMO}

O presente artigo tem em vista interpretar a pandemia desde uma reflexão acerca da noção de hiper-realidade, presente na filosofia do autor francês Jean Baudrillard. Para tanto, serão trabalhadas, de início, noções do pensamento de Martin Heidegger, principalmente seu desenvolvimento acerca do esquecimento da questão do ser na era da técnica. O objetivo de tal explanação é a indicação de uma passagem da técnica para a simulação, em um diagnóstico sugerido por Baudrillard ao longo de seus textos. A partir da noção de hiper-realidade e simulação, será proposta a tese de que o Sars-Cov-2 é um simulacro global que consuma a expansão do Ocidente como abandono radical de qualquer relação possível com o real.

Palavras-chave: Pandemia. Hiper-realidade. Jean Baudrillard. Martin Heidegger. Simulacros. Simulação.

\section{ABSTRACT}

This article aims to interpret the pandemic from a reflection on the notion of hyperreality, present in the philosophy of the French author Jean Baudrillard. For that, notions of Martin Heidegger's thought will be worked on, mainly his development about

\footnotetext{
${ }^{1}$ Doutor em Filosofia pela Universidade Federal do Rio de Janeiro. Atua como professor substituto na Universidade do Estado do Rio de Janeiro.
} 
the being in the age of technique. The purpose of such an explanation is to indicate a transition from technique to simulation, in a diagnosis suggested by Baudrillard throughout his texts. Based on the notion of hyper-reality and simulation, will be raised the thesis that the Sars-Cov-2 is a global simulacrum. It ends the expansion of the West as a radical abandonment of any possible relationship with the real.

Keywords: Pandemic. Hyper-reality. Jean Baudrillard. Martin Heidegger. Simulacrum. Simulation.

\section{INTRODUÇÃO}

A tarefa de pensar o acontecimento da pandemia causada pelo vírus Sars-Cov-2, origem da doença COVID-19, não se mostra menos que complexa e enigmática. Não por motivos relacionados à questão epidemiológica e da constituição do vírus, ou bem de sua origem e de cura da doença, e sim por conta de como tal pandemia mobiliza e expõe questões contemporâneas de difícil visualização. O presente artigo, portanto, não empreende uma espécie de filosofia da biologia, isto é, não busca levantar questões acerca da doença ou relativas ao vírus em si, mas tem por finalidade expor como a pandemia sedimenta acontecimentos hiper-reais a nível global. Para dar seguimento à proposta do presente artigo será necessário abrir um canal de diálogo entre o pensamento de Jean Baudrillard e Martin Heidegger. O que se tem em vista aqui é a tese segundo a qual a noção baudrillardiana de hiper-realidade dialoga de forma essencial com a questão da verdade e da técnica de Heidegger. Será visto que hiper-realidade pode ser interpretada como uma espécie de sucessão ao niilismo do abandono da questão do ser, instaurando uma região total de supra realidade, que se descola e se põe além da noção de verdade.

De início, ficará fundamentado o argumento heideggeriano relativo ao abandono da questão do ser, em voga naquilo que nomeia de era da técnica. Desta feita, a noção de verdade ficará evidenciada como o elemento em questão na mutação histórica que justamente abre o campo do contemporâneo como espaço disruptivo de qualquer possibilidade de sua [da verdade] centralidade. Somente a partir daí se torna possível a compreensão da transição que o pensador francês opera entre a noção de real e hiperreal. A maneira com que Baudrillard posiciona o Ocidente em um cenário pós-niilista uma vez que niilista ao extremo - curiosamente vaticina um irreversível e irresistível 
passar ao largo da possibilidade de retomada da distinção entre verdadeiro e falso ${ }^{2}$. Nesse sentido, compreender o pós-niilismo baudrillardiano - via abandono da questão do ser em Heidegger - possibilita visualizar que a ruptura com o lastro de negatividade do real abre um campo de jogo no qual tudo se insere para além de valor, de medida, de erro e acerto, de verdadeiro e de falso: tudo se dá pela presença total de essências derivadas que se dão sob o signo da simulação. A simulação é exatamente aquilo que permite que o real agora seja hiper-real, isto é, uma presença sem transcendência que obnubila a possibilidade simples do real por meio um fac-símile: o simulacro. Para Baudrillard o real é aquilo que jamais conseguiria alçar-se à condição de presença total, justamente aquilo que o simulacro concretiza. Para Baudrillard, o real é ambíguo. Ele é aquilo que guarda em si mistérios, reservas, diferenças e é aporte metafísico de uma gama de investidas filosóficas e científicas. Por sua vez, o hiper-real é o cenário simulado das essências, espaço onde todos os entes parecem estar totalmente presentes quando, em realidade, não estão. O hiper-real é um engendramento de conformações espectrais que faz uso de essências emudecidas em um jogo de aparências que se totaliza no mundo ocidental pós-niilista.

Em suma, ao perfazer a análise dos pensamentos de Heidegger e Baudrillard será indicado que ambos os autores trabalham com a ideia de desertificação do real: Heidegger na medida em que identifica o emudecimento da questão do ser e Baudrillard ao passo que revela um mundo de simulacros, onde não há mais essências. $\mathrm{O}$ real é aquilo que se revela ambiguamente no des-velamento e na abstração de sua falsa obviedade. Tal mobilidade do real é o tempo; é a poética do tecer e destecer do destino; é o desatino luminoso e obscuro das questões que este mesmo real traz. Em contraste, para ambos os filósofos, o contemporâneo aparece aí como o espaço da inessência e do espectral: aparece como deserto do real. Nesse escopo, a pandemia surge, então, como uma espécie de marco antropológico que torna o movimento desertificador do real não mais restrito a determinados povos, setores ou regiões - por exemplo, como ao que se acostumou chamar de Ocidente -, mas por meio da pandemia todo o espaço ocidental se

\footnotetext{
${ }^{2}$ Curioso observar como a superação do niilismo para Baudrillard, em contraste com o pensamento ontológico heideggeriano, não reserva nenhuma retomada de questões filosóficas fundamentais, mas sim uma espécie de soterramento fundamental de qualquer lastro de ligação com a verdade em seu largo espectro de entendimento.
} 
alastra e se emenda de forma planetária, em um fenômeno que traz à baila um simulacro global e, por isso, a inauguração de um deserto a nível planetário.

\section{DA VERDADE AO VAZIO: HEIDEGGER E A TÉCNICA}

Basicamente, Heidegger reconhece na tradição ocidental um problema bem específico: o problema do esquecimento da diferença ontológica. De Platão até Nietzsche, Heidegger visualiza uma miríade ampla de questões filosóficas distintas e de modos distintos de esquecimento de tal diferença. O modo como cada um deles deixa de considerar a diferença ontológica em sua plenitude não será aqui minuciosamente explorado. O decisivo é que, para Heidegger, o projeto filosófico da tradição é marcado por esse esquecimento em comum. Como foi visto acima, diferença ontológica aponta para a completa, total e radical diferença entre ser e ente. O problema se constitui exatamente no modo como a tradição compreendeu tal diferença entre ser e ente, e no modo como considerou, ou melhor, deixou de considerar o essenciar-se do ser. É assim na medida em que, a princípio considerando a diferença entre ser e ente, a tradição ocidental tentou fixar de uma vez por todas o essenciar-se do ser em medidas ontológicas estáticas, algo que por natureza simplesmente está fora de qualquer possibilidade de sucesso. A partir do espanto inicial grego com a abertura da physis em seu des-velamento (a-létheia), repetidamente abdicou-se do caráter velado daquilo que por si mesmo surge em direção à sua tematização explícita mostradora. Dentro da interpretação heideggeriana da história da filosofia, há termos fundamentais que servem como índice de esquecimento de ser. A ideia platônica, a ousia aristotélica, o Deus medieval etc., apontam para o esquecimento da diferença ontológica e indicam a pretensão da tradição em alcançar definitivamente o ser do que se abre, pareando ser e ente.

Para tal característica da tradição, Heidegger cunha a expressão "onto-teológica” (2006, p. 56), isto é, ela tem o caráter de discurso (lógica) que tematiza o ser (onto), determinando-o como ente supremo (teo). Em suma, ele reforça o fato de a tradição ocidental nunca ter considerado de maneira suficiente a diferença entre ser e ente, tendo tematizado o ser sempre ao modo da entidade. Portanto, Heidegger pensa o percurso da tradição ocidental como o caminho da consumação metafísica onto-teológica, em um envio que leva dos pré-socráticos até Nietzsche. Através de um 
riquíssimo diálogo com a tradição filosófica, Heidegger pretende demonstrar, por meio de um "passo atrás", o fundo impensado de tudo o que pela tradição foi pensado para, através de uma reconsideração da diferença ontológica, apontar a constituição onto-teológica da tradição ocidental. Heidegger indica, com isso, que ao esquecer da diferença ontológica a tradição filosófica perde de vista sua questão fundamental, o solo a partir do qual qualquer questão se torna digna de ser pensada: a questão do ser. O modo como Heidegger lê a filosofia até seus dias aponta na direção não apenas do esquecimento da diferença ontológica, mas fundamentalmente do abandono da questão do ser, que alcança sua consumação na era da técnica

Tal modo de lidar com a história da filosofia marca o trabalho heideggeriano de maneira fundamental. Grande parte de seus textos se voltam para apreciações acerca do modo como os filósofos da tradição são compreendidos como vozes da metafísica do envio do ser e tomam parte no esquecimento da questão do ser e da diferença ontológica. Deste modo, quando Heidegger interpreta tais filósofos, sempre o faz desde a perspectiva de tal esquecimento e abandono, uma vez que esse é o ponto que sua própria investigação filosófica descortina como argumento fundamental e eixo em torno do qual toda a confrontação com a história da filosofia vai acontecer. Se o destino do Ocidente é marcado como envio do ser balizado na metafísica onto-teo-lógica, os pensadores dessa tradição são agora entendidos como momentos do apelo do ser em seu envio. É nesse escopo que se dá a confrontação de Heidegger com a tradição filosófica. Desta forma, a confrontação (Auseinandersetzung) de Heidegger com a tradição é, na verdade, um exercício hermenêutico que visa demarcar o lugar dos filósofos da tradição em relação à questão do ser.

Algumas palavras são marcas desse processo de desdobramento do ser em seu esquecimento, talvez a principal delas seja a palavra "verdade". De início, Alétheia é o termo que Heidegger identifica como central e que sofre transformação paulatina indicando por meio de si o sentido de pleno do abandono do ser. A-létheia é composta pelo prefixo "alfa", delineando o sentido de negação, e pelo termo lethe, significando algo como encobrimento, velamento. Portanto, em seu entendimento mais primordial a alétheia grega aceita e reconhece na mostração dos entes em geral um caráter de retraimento e velamento. Esse caráter de obscuridade inerente à mostração confere a ela o sentido de des-velamento, des-encobrimento, em detrimento de um sentido que se 
restrinja à mera presença dos entes no espaço. $\mathrm{O}$ ente se des-vela. Ele se permite mostrar ao invés de permanecer desconhecido. Em seu entendimento já está reunido um não-se-mostrar essencial próprio àquilo que se mostra. Verdade na Grécia tem, portanto, o sentido de um mostrar-se do ente, que é permitido em uma possibilitação recíproca entre velamento e desvelamento, no qual cada um desses termos garante ao outro o vigor de sua essência, de modo que os dois só se desempenham juntos (HEIDEGGER, 1998, p. 143). O que era digno de ser pensado era a physis, a natureza em sua mostração mesma que reunia em torno de si o mistério inerente ao acontecimento da verdade. A própria physis era o espaço virgem da alétheia, e o homem era o seu intérprete. A physis era apreciada em seu próprio movimento misterioso, deveniente em meio a um embate (polemos) harmônico entre velamento e desvelamento (HEIDEGGER, 1999, p. 44-45). Um movimento de criação e destruição, de nascimento e perecimento. Desta forma, nos primórdios da filosofia grega há a visualização de uma reserva própria à mostração da physis em seu devir, que assegura os contornos de uma noção de verdade que permite espaço para uma retração fundamental do aberto. Heidegger delimita esse modo da physis se revelar como primeiro envio do ser. No entanto, Heidegger reconhece nesse primeiro aceno apropriador do ser já uma incompreensão na recepção grega em relação a esse modo de essenciação, que abre a medida ekstática para a possibilidade posterior de sua decaída. O primeiro aceno do ser em seu ineditismo na alétheia da physis grega fornece os caminhos de sua incompreensão tardia. Se alétheia diz de um abrir que fundamentalmente se retrai nesse mostrar mesmo, a tradição filosófica tende a se fixar na permanência disso que é aberto. Nessa direção, pode-se pensar, por exemplo, a idea platônica como modo inicial desse desdobramento que se fixa na constância do que se abre de modo que "A palavra idea significa o visto no visível, o visto que alguma coisa oferece. O que se oferece é o aspecto, eidos, do que vem ao encontro" (HEIDEGGER, 1999, p. 202). Idea se dá como eidos, isto é, como elemento estável constituidor da essência daquilo que permanece no aparecer do objeto. Tal fixação no que se apresenta como permanente e durável na physis se torna algo que se desdobra também no interior do pensamento aristotélico. A ousia é esse elemento que surge como presença constante e essencial do ente. Na medida em que a dimensão de constância essencial do ente se dá por meio da ousia (ou ideia), ocorre conjuntamente a essa indicação da constância essencial do ente uma cisão em relação aos seus elementos contingenciais. Entra em 
curso, então, a cisão ser e aparência, cisão na qual o ser daquilo que se revela agora se confunde com a sua estabilidade (ousia/idea) e a aparência com os seus elementos acidentais. Advém daí a noção de que a aparência superficial dos entes se mostra enquanto o elemento que sustenta a essência dos entes que se esconde e precisa ser filosoficamente descoberta e desdobrada. Perde-se a compreensão originária de copertencimento entre velamento e desvelamento. Deste modo, physis se inscreve paulatinamente como "física". Abre-se a possibilidade de compreensão do velamento do aberto como um esconderijo da essência daquilo que se abre, de modo que parte fundamental do esforço filosófico passa a ser o de não se deter em nenhum elemento conjuntural e acidental dessa mesma "física", mas o de voltar-se para os seus fundamentos inaparentes. Isso torna necessário o pôr-se para além da física mesma na busca desses princípios. A filosofia agora não deve se deter em nenhum domínio particular (aparente) da natureza, mas em seu elemento fundamental. Para isso precisa ir além (meta) dessa aparência superficial da natureza (physis no sentido de física). Com isso, meta-física passa a ser o "nome para designar o centro decisivo e o núcleo de toda filosofia" (HEIDEGGER, 1999, p. 47). Como desdobramento do aceno do ser no pensamento grego como alétheia, a filosofia agora desdobra-se fundamentalmente como metafísica. Isso se dá de tal forma que esse desdobramento acontece a partir de possibilidades abertas pelo próprio modo de compreensão grego, que abre o campo de desdobramento da filosofia (metafísica) como "eco" - a cada vez um tanto menos audível - em torno desse aceno do ser em seu princípio na alétheia grega. A partir disso, com a latinização do mundo grego tais questões são desdobradas por meio de outros contornos.

Para Heidegger, a partir do momento em que os romanos se assenhoram do pensamento grego sob a perspectiva imperial, automaticamente entra em curso um empobrecimento das questões originárias em função de uma falta de sensibilidade em relação ao que na Grécia estava sendo indicado. Nesse sentido, a partir de alétheia, agora se tem a compreensão de verdade como veritas e, com isso, um novo entendimento que ignora o que de essencial havia sido despertado no pensamento grego: o retraimento daquilo que se presentifica como necessário para a mostração em si. No entanto, como foi visto, esse modo de compreensão já fora aberto como possibilidade pela indicação da metafísica grega. O ponto é que o que tem lugar nessa 
latinização é a equiparação da própria retração com o modo de ser do ente que se mostra. A retração aponta para uma duplicata do ente no além do ente que é o fundamento. Com isso, a veritas traz consigo o entendimento de substância (substantia) como algo inerente a cada ente e que confere a cada um deles sua própria validade enquanto ente fundado pelo ente supremo: Deus. Para Heidegger, esse processo de transformação da alétheia em veritas é decisivo para o desenrolar do destino ocidental, porque é a partir de então que mundo começa a se desenhar como um espaço simplesmente dado ocasionado, não pela co-originária retração do velamento, mas pelo ente supremo (Deus). Esse tipo de configuração predomina na Idade Média, e sua organização se volta para o esforço filosófico de compreensão das relações entre o ente supremo e suas criações. Esse evento é voz de um nivelamento da ideia de ser e ente, na medida em que posiciona o Deus criador como fonte produtora e mantenedora de cada ente em sua substancialidade. Na transformação de alétheia para veritas, a aceitação do velamento enquanto parte essencial da verdade deixa de ser compreendida em sua radicalidade e, com isso, o velamento passa a ser tal qual a mostração, só que "por detrás" do real, produzindo-o.

$\mathrm{Na}$ modernidade, uma segunda transformação tem lugar, levando da veritas medieval à certitudo (certeza). Se na veritas os entes presentes no mundo secular são cada qual uma substância que se relacionam a uma fonte produtora de tais essências, na transformação do horizonte compreensivo que tem lugar na passagem da Idade Média para a Moderna, há o radical pôr em dúvida dessa fundamentação, que precisa agora ser certificada em sua validade. Esse radical pôr em dúvida atende à reivindicação em torno da busca por certeza acerca do fundamento, agora não mais vinculada à revelação cristã, que entra radicalmente em questionamento em nome da razão como elemento revelador da verdade do ente.

A reivindicação surge daquela liberação do homem na qual ele se liberta da vinculação à verdade da revelação cristã e à doutrina da Igreja, para uma legislação que se põe com base em si mesma e que é para si mesmo (HEIDEGGER, 1998, p. 132).

Determinando a decisão histórica de:

No interior da história da modernidade e como a história da humanidade moderna, o homem enquanto centro e a medida procura colocar a si mesmo a cada vez por toda a parte na posição de domínio, isto é, empreender o asseguramento desse domínio. Para tanto, é necessário que ele se assegure cada vez mais de suas próprias capacidades e de seus próprios meios de 
dominação, deixando-os constantemente prontos uma vez mais para uma disponibilidade incondicionada (HEIDEGGER, 2014, p. 560).

Certeza, com isso, atende à pretensão de domínio do ente a partir de um reposicionamento da ideia de fundamento. Centrado no pensamento de Descartes, uma vez que o mesmo "antecipou o fundamento metafísico da modernidade" (HEIDEGGER, 2014, p. 561), Heidegger identifica na compreensão de verdade como certeza, que se apresenta em meio ao cartesianismo, a pretensão de domínio do ente e a centralidade do homem nesse processo. Isso se dá porque, a partir do momento em que a validade dos entes em geral passa a ser radicalmente questionada, imediatamente a subjetividade responsável por essa representação dos entes também passa a ser questionada em sua validade, de modo que se torna necessário saber precisamente "o que é" essa subjetividade e de que maneira ela está apta a desempenhar verdadeiramente a representação do ente em sua verdade. Aquilo que o pensamento moderno põe em curso é justamente a tentativa de certificação plena do sujeito que representa os entes, de modo que seja possível, antes de tudo, certificar-se de si mesmo para que se possa ter acesso ao mundo que se representa por meio dessa subjetividade. Não apenas isso, mas subsunção de todo e qualquer ente ao ente capaz de ser o primeiro ente detentor de alguma substancialidade confiável: o homem, agora definido como animal racional. Essa é a principal mudança que caracteriza a passagem da Idade Média para a Idade Moderna. Há uma mudança de acento: perde força o Deus produtor das substâncias em geral e o homem torna-se o ponto de equilíbrio do real. Isso se dá justamente por ser ele [homem], teoricamente, o ente capaz de ser o centro confiável do acontecimento dos entes em geral, torna-se - subvertendo a sentença de Protágoras - "a medida de todas as coisas". O sujeito humano, por meio do uso apropriado da razão, é esse pilar de sustentação inabalável, que erige a modernidade. Portanto, tal pôr em dúvida os entes só ganha um solo de respostas seguras por meio do homem, de modo que o pensamento de Descartes é o próprio "fundar o fundamento metafísico da liberação do homem para o cerne da nova liberdade como autolegislação segura de si mesma" (HEIDEGGER, 1998, p. 132). O que acontece na modernidade é que os entes em geral passam a ser encarados como entes passivamente expostos à inquirição humana, o primeiro entre todos os entes possuidor de alguma substancialidade segura e capaz de se assegurar dos demais entes por meio de si. "Representar é assegurar" (HEIDEGGER, 2014, p. 565). Isso não no sentido de que os entes não possuem estabilidade ontológica e existem 
apenas relativamente ao capricho do representar humano - que faria do ente aquilo que essa representação mesma quereria que eles fossem -, mas que eles agora estão dispostos para um assenhoramento racional da subjetividade humana. Quando mundo se dá desde certeza, o acento em relação à compreensão dos entes em geral se volta para o sujeito humano em sua vocação racional para o domínio do ente, pois é por meio da subjetividade do homem que a sua expressão correta se torna possível.

O homem é o fundamento insigne que se encontra na base de toda representação do ente e de sua verdade, o fundamento sobre o qual todo representar e seu representado são e precisam ser posicionados, caso devam ter uma estabilidade e uma consistência. O homem é subiectum nesse sentido insigne. O nome e o conceito de "sujeito" passam agora para a nova significação e se transformam no nome próprio e no termo essencial para o homem. Isso significa: todos os entes não humanos transformam-se em objeto para este sujeito (HEIDEGGER, 2014, p. 576).

Os entes em geral agora se encontram simplesmente dados em um espaço físico gratuito e precisam ser certificados acerca de sua presença real por meio do ente primeiramente real. Metodologicamente, a certeza se alcança pela razão, que garante ao homem a sua essência como animal racional e ao mundo a sua validade como objeto a ser dominado. Sob a determinação do animal racional, mundo, agora, se torna o espaço de jogo onde o homem desempenha toda a sua genialidade teórica. Com isso, também o homem se torna objeto de si mesmo e passa a ser entendido como apto a ser predicado racionalmente. $\mathrm{O}$ ente agora é um mero por si subsistente dotado de características quaisquer, capaz de ser contido pela razão. Na medida em que não há mais espaço para retração - o espaço agora é total em sua gratuidade -, tudo pode ser conhecido em suas propriedades e a ciência se torna a palavra de ordem. Sob a égide do método correto, nada fica sem resposta. Todo mistério tem de ser desvendado, ou se ainda há mistério, ele é apenas o combustível que fomenta uma nova série de descobertas. O que se busca nesse momento não é mais uma justificativa divina para o mundo, mas a certeza comprovável das inquirições e o domínio amplo e irrestrito de todas as variáveis com as quais o homem se depara durante tal empresa. $\mathrm{O}$ homem passa a ser o protagonista do mundo e toda a fé deposita-se na sua capacidade de estabelecer certezas a partir de si como o ente soberano dos entes. O mundo histórico que se abre na Idade Moderna consuma a passagem da veritas para a certeza, nesse cenário a ciência surge como voz suprema. Tal mudança tem como solo seguro fundador o solipsismo da subjetividade como primeiro elemento a ser provado em sua validade, e que inicia toda a série de 
certezas subsequentes submissas a essa subjetividade. Agora o homem dispõe do ente. Os entes se dão como instâncias a serem dominadas. É por meio da subjetividade como elemento posicionador primordial que o homem desvenda o ente e o determina tendo como lastro de confiança o seu poderio teórico-científico. Todos os entes agora são posicionados pela subjetividade, que se mostra como essência ordenadora das demais essências.

Para compreender o desdobramento da modernidade em sua figura última na era da técnica, é necessário se referir ao modo como Heidegger, surpreendentemente, lê Nietzsche como o filósofo que é marca de um desdobramento radical do pensamento cartesiano no que tange à radicalização da metafísica da subjetividade moderna. Uma vez que Descartes é a voz filosófica da centralidade da subjetividade humana no processo de domínio dos entes, para Heidegger, Nietzsche de algum modo radicaliza tal noção e a leva aos limites de suas possibilidades. Se a partir de Descartes há o posicionamento do homem como ente que em essência domina os entes, é em Nietzsche que essa relação se torna radicalmente explícita e, ao mesmo tempo, se mostra como ilusória. No texto Nietzsche, Heidegger elenca cinco expressões fundamentais de seu pensamento: niilismo, vontade de poder, eterno retorno, além-do-homem e justiça.

Em Descartes se faz presente uma importante mudança dos princípios metafísicos tradicionais. Quando verdade se faz compreender como vinculada à razão humana, que posiciona por meio de si os demais entes, a radicalidade desse ato destrona a normatividade suprassensível do Deus produtor medieval. Nietzsche abaliza mais radicalmente isso com a sua indicação da morte de Deus: o fundamento suprassensível perde força atuante e libera a existência humana dos valores tradicionais, pois perderam totalmente seu lastro de fundamento. Tal esvaziamento dos valores tradicionais é a própria essência do termo niilismo. O niilismo como colapso dos valores tradicionais abre a necessidade de produção de novos valores (transvaloração dos valores). De acordo com Nietzsche, a produção de novos valores exige alguma dinâmica constituinte que, de fato, produza novos valores, afinal Deus morreu. O cerne produtor de novos valores é o que Nietzsche chama de vontade de poder. É através da vontade de poder que novos valores são produzidos por meio de uma emancipação e afirmação da vida em relação ao modelo adoecido do cristianismo. Para Nietzsche, a vida cristã é um corpo vital adoecido e despotencializado na medida em que deposita em uma instância 
transcendental a face verdadeira do real, relegando a vida a um papel de ressentimento por ser o que é, na medida em que sua dignidade ontológica é debitária de um outro mundo, esse sim verdadeiro e incorruptível. Uma vez que esse pilar de sustentação ontológico do mundo se encontra morto, é preciso pensar o como do processo de formação do ser dos entes nesse novo mundo que se abre. Desta forma, é preciso compreender, dentro da interpretação heideggeriana, o modo como vontade de poder se estabelece, para compreender como novos valores - que se confundem agora com o ser dos entes - são conformados. Em relação à vontade de poder, Heidegger indica um copertencimento:

\begin{abstract}
O poder, contudo, não é a meta para a qual a vontade quer se dirigir em primeiro lugar como algo que se encontra fora dela. A vontade não aspira ao poder, mas já se essencializa e só se essencializa na região essencial do poder. Não obstante, a vontade não é simplesmente poder e o poder não é simplesmente vontade. Ao contrário, o que vale é, antes: a essência do poder é vontade de poder e a essência da vontade é vontade de poder. [...] A junção das palavras na expressão "vontade de poder" denomina precisamente a simplicidade inseparável de uma essência articulada e única: a essência do poder (CABRAL, 2015, p. 162).
\end{abstract}

Vontade de poder é o próprio modo como vontade e poder, em sendo âmbitos distintos, se pertencem. Não apenas isso, mas vontade de poder é o próprio modus operandi em meio ao qual o ente se estabelece no seu devir. Com a morte de Deus e a liberação em relação aos valores tradicionalmente estabelecidos, o processo que se abre como produtor de novos valores é a dinâmica da vontade de poder. A vontade de poder se dá como o próprio modo constituidor do ser dos entes: se os entes agora se veem radicalmente liberados em seu devir, prescindindo do fundamento de um Deus morto, a vontade de poder se dá de forma irrestrita e como incessante autossuperação. Na medida em que não há remissão a nenhum tipo de fundamento que estabilize o ente, cada ente nesse cenário apenas "vale" de acordo com a paisagem em meio à qual ele se descortina como ente. Quem posiciona o valor dos entes é a resultante das forças atuantes no constante combate entre os corpos vitais que configuram o real por meio da dinâmica da vontade de poder. Portanto, a vontade de poder em seu constante valorar - por meio do embate entre forças que se afirmam na pretensão de hegemonia -, posiciona o ser dos entes como aquilo que a cada vez vale como resultado desse embate mesmo. É justamente aí que Heidegger visualiza o elo do pensamento de Nietzsche como desdobramento radical da metafísica da subjetividade moderna. O valor (ser) dos entes agora é posto como resultado do embate das forças que o corpo vital do homem é. É 
assim porque o homem corpora como assunção de novos valores e assim o homem determina o valor (ser) de tudo que é nesse corporar valorativo mesmo. Como a vontade de poder se dá como um perpetuar-se sem travas, tal subjetividade se dá como vontade incondicionada que sujeita o valor (ser) de tudo que é apenas a si mesma em seu processo constituidor como vontade de poder.

A partir disso, eterno retorno surge também como uma expressão fundamental da leitura que Heidegger empreende de Nietzsche. Eterno retorno aparece como o semlimite de desdobramento da dinâmica formadora de valores da vontade de poder: não há dimensão do tempo que fuja dessa dinâmica instauradora. Se não há âmbito suprassensível do real que estabilize a relação de devir por meio de alguma medida unificadora, esse espaço se encontra agora liberto de todos os limites temporais que poderiam conter a vontade de poder. A volatilidade do que se instala como valor relativo dos entes se pereniza, de modo que não há solo firme que contenha o constante rearmar das conjunturas valorativas. O eterno retorno abre o campo irrestrito de manutenção da vontade de poder como modo fundamental de posicionamento do valor relativo (ser) dos entes. A partir do eterno retorno, que abre tal campo irrestrito para o embate das forças, a vontade de poder se vê legitimada como o próprio modo de valoração dos entes para além de qualquer trava. Isso quer dizer que tudo agora é justificado pela vontade de poder como o fiel da balança dos valores (ser) dos entes.

Tudo que é e pode ser está justificado na vontade de poder, que, engendrando valor, assegura-se de seu desenvolvimento autossuperador. Ao mesmo tempo, tudo o que se efetiva está correto, pois merece se determinar desse modo, já que se efetivou sob a certificação da vontade de poder. [...] A vontade de poder, portanto, não permite pensar a verdade como adequação entre discurso e estado de fato dos entes, mas permite pensar a verdade como adequação de todo ente à justa medida de sua dinâmica de realização fornecida pela vontade de poder. (CABRAL, 2015, p. 165-166).

A justiça então tem a ver com a legitimidade de um tal processo constituinte de valores. A verdade do ser dos entes se vê confundida com esse processo de fornecimento de valores pela vontade de poder, agora legitimada como único modo autêntico de instauração de valores, que por meio de um livre embate se estabelecem. A verdade e o ser daquilo que é, se tornam aquilo que, com justeza, se estabelecem como relativamente hegemônico em determinada conjuntura. Se o valor (ser) de um ente se sustenta enquanto tal, isto quer dizer que, com justiça, ele se mantém, pois se impõe frente ao assédio por hegemonia de outros valores e nesse embate permanece como 
valor hegemônico. Desta forma, aquilo que se impõe como valor (ser) dos entes o faz sempre de forma legítima enquanto for o caso. Por fim, a última expressão fundamental da interpretação heideggeriana de Nietzsche é o além-homem. Além-homem é o tipo vital que assume e concretiza por meio de si a transvaloração dos valores metafísicos da tradição e perfaz concretamente sua própria existência como o lugar do devir como criação de valores e, com isso, da determinação do ser dos entes.

Tal modo de interpretação do pensamento de Nietzsche o insere como desdobramento radical de Descartes no projeto de "fundar o fundamento metafísico da liberação do homem para o cerne da nova liberdade como autolegislação segura de si mesma" do pensador francês. Essa interpretação insere Nietzsche como voz da consumação do destino do Ocidente como abandono da questão do ser e como voz filosófica da era da técnica como a época histórica dessa consumação. A dinâmica da vontade de poder, legitimada sempre a cada vez pelo eterno retorno, configura o radical abandono da questão ontológica, de modo que é apenas de forma ôntica que o valor (ser) dos entes se estabelece, tendo no corpo vital do além-homem o seu "lugar" de constituição.

Com isso, para Heidegger, o pensamento de Nietzsche consuma o radical rompimento com a questão ontológica, uma vez que o ser dos entes acontece como valor fugaz em suas determinações conjunturais, agora totalmente sem remissão a alguma constituição ontológica que não o posicionamento valorativo da vontade de poder. Onde isso tem lugar, os entes se determinam sem lastro ontológico, apenas como configurações e reconfigurações ônticas advindas de um embate que posiciona seus valores (ser) relativos. Heidegger vê aí o fato de a era da técnica se dar como acontecimento apropriador da desapropriação radical do ser, o que instaura a subjetividade incondicionada da técnica como vontade incondicionada na lida posicionadora do valor (ser) dos entes. O ser se retira e o espaço aparece como gratuidade disponível ao domínio da subjetividade incondicionada, que posiciona os entes por meio de si. Deste modo, à luz da subjetividade incondicionada formadora de valor (ser) dos entes imposta pela interpretação heideggeriana de Nietzsche, é possível compreender como Heidegger identifica a era da técnica como voz de um vazio radical. $\mathrm{O}$ vazio em questão tem a ver exatamente com um radical abandono da questão da verdade. Em um processo que leva da alétheia à vontade de poder, o cenário 
contemporâneo abre um niilismo marcado pelo passar ao largo da própria questão da verdade enquanto questão.

Grosso modo, em tal consumação do envio histórico ocidental como abandono radical da questão da verdade via esquecimento da diferença ontológica e da questão do ser, o que "resta" ao ser-aí humano é a entrega ao mero ente em dinâmica leviana. Dinâmica essa que, na medida em que não conhece nada para além de seu próprio movimento, finda por autonomizar-se sem travamento algum. O perigo que Heidegger reconhece em tal cenário é o perigo de tal movimento não experimentar rompimento algum, sempre se rearticulando em novas configurações contingenciais. O que acontece em um processo como esse é que o "elo" entre homem e mundo, e consequentemente o "elo" do homem consigo mesmo, se obscurece. Como desdobramento da modernidade, Heidegger delimita o contemporâneo como lugar do vazio. $\mathrm{O}$ vazio se dá na medida em que paulatinamente o processo de certificação do real se perde e há a entrega de uma época que não experimenta mais ente algum: o espaço do aí se dá como radical gratuidade indiferente disponível. O movimento que leva da modernidade consumada, ou era da técnica para Heidegger, se afina com um exemplo que pode ajudar: uma pessoa que é cega, no fundo, permanece enxergando, afinal um cego usa uma bengala porque de fato continua, em alguma medida, vendo: ele sabe que à sua frente existe algo e por isso usa a bengala para considerar que seus passos o levam para algum lugar e não são dados randomicamente. $\mathrm{O}$ ponto é que, da passagem do moderno ao vazio, o homem passa de uma cegueira em relação ao ente para o vazio da desertificação. Já não há remissão a ente algum. Seria como um cego que dispensa a bengala por achar que a ausência daquilo que não vê é o que há para ser experimentado. Ele não chega nem a se perder, pois já não sabe mais de tal perda do ente: se esquece do esquecimento de sua essência como abertura relacional com mundo e ao modo mesmo dessa abertura. O que impera agora é a imposição da própria dinâmica de configurações contingenciais estabelecidas de maneira conjuntural no que tange à sua gratuidade enquanto dinâmica mesma, isto é, sem lastro ontológico. Verdade aqui é aquilo que a cada vez é o caso. Não se experimenta verdade como desvelamento (alétheia) e ela não mais envolve algum modo de certificação, no sentido de uma adequação entre o juízo racional e coisa a ser explicada (adaequatio). Tal abandono da questão da verdade, que na economia do 
pensamento heideggeriano se confunde com a questão do ser, é caminho para a compreensão da noção de hiper-real em Jean Baudrillard.

\section{DO VAZIO À SIMULAÇÃO: BAUDRILLARD E A HIPER-REALIDADE}

O pensamento baudrillardiano é extremamente complexo para se apresentar segundo um resumo linear e totalmente estruturado. Seus escritos transitam por diversos termos cuja criação de um léxico ordenado certamente se apresentaria como um desserviço ao estilo de escrita rebelde e arredio do pensador francês. Tal modo incerto de escrita é, sem dúvida, parte de seu argumento. De todo modo, é necessária uma breve apresentação de sua filosofia por meio de uma confrontação com a noção de niilismo em Nietzsche e em Heidegger. O intuito de tal confrontação é estabelecer um caminho de análise que mantém em vista o que já foi tematizado até aqui, acerca do desenvolvimento da noção de verdade na linearidade do destino ocidental e como algum modo de sucessão de tal destino se vê abalada e impossibilitada por meio do diagnóstico filosófico de Baudrillard.

Ao final da primeira parte do texto, chegou-se ao reconhecimento de uma crise naquilo que se refere ao elemento central do Ocidente: a busca pela verdade. Tal termo [verdade], a partir de Nietzsche, se torna tudo aquilo que se impõe a cada vez como sendo o caso. Isso se dá exatamente como fenômeno derivado da morte de Deus, isto é, da perda de um fundamento metafísico de sustentação da unicidade conformativa do mundo. Sem seu pilar de sustentação tradicional, verdade passa a ser aquilo que se impõe como tal. Portanto, Nietzsche já aponta para uma forma de verdade que identifica no seu modo de ser uma ruptura com as bases tradicionais do Ocidente: Deus como fundamento. O niilismo nietzscheano é uma ruptura que não deve ser lamentada, mas afirmada pelo além-homem que compreende e aceita a dinâmica vital que tal estado de coisas empreende. Portanto, para Nietzsche, há escape possível de uma espécie de niilismo indiferente, que julga a ausência de fundamento como irremediavelmente trágica. Esse escape se dá pelo e no além-homem. Somente pela postura afirmativa da vida na sua ausência de origem se destrói o niilismo da despotencialização vital oriunda de uma saudade de fundamento. O ponto é que a interpretação heideggeriana de Nietzsche identifica outra espécie de niilismo: o niilismo do vazio. O niilismo do vazio - que é completamente diferente do Nada - tem a ver com o passar ao largo da questão 
fundamental da existência humana, qual seja, a questão do ser. Heidegger identifica uma desistência pela busca do sentido do ser, de modo que seu pensamento é uma tentativa de retomada da essência ocidental, isto é, da tematização ontológica via pergunta pelo sentido do ser. O vazio seria superável pela voz silenciosa e retumbante do ser, recolocando o Ocidente nos eixos e "salvando" da era da técnica. Para Heidegger, o ser-aí ao se deixar apropriar pela verdade do ser insere o corte que retira do vazio do tédio e, com isso, supera a metafísica da técnica - da qual o próprio Nietzsche faria parte como voz derradeira. Há, portanto, uma salvação para o niilismo do vazio heideggeriano, isto é, pelo acontecimento apropriador do ser. Por fim, o pensamento de Jean Baudrillard insere um terceiro tipo de niilismo: o niilismo da simulação do real. Tido como pessimista, Baudrillard afirma - como será visto adiante que para esse niilismo não há escapatória nem saídas possíveis uma vez que todas as ações que surgem neste campo surgem como simulação e trazem consigo a aniquilação de qualquer tipo de corte transcendental possível. Por ora, o ponto é compreender o que é simulação. Em uma definição direta "simular é fingir ter o que não se tem" (Baudrillard, 1991, p. 09). A par dessa definição reta e em relação com o que já foi visto até aqui, o que não se tem no contemporâneo é o real enquanto acontecimento com lastro de verdade, justamente o que abre o campo para a simulação. Para Baudrillard, já não há des-velamento (alétheia) possível da verdade, nem adequação (adaequatio) entre intelecto e coisa, radicalmente tudo se dá como simulação de realidade ${ }^{3}$. Mesmo a noção de uma representação da realidade fica fora de circuito, pois já não há o elemento em-si da coisa, apenas seu signo simulado. Há, sim, a produção de uma rede simbólica na qual todo signo rompe relações com a consistência de sua validade mesma como significado. A saída desse cenário para sua superação perde justamente o elemento de corte que seria necessário para tal transição. Já não há Deus ex machina que altere o roteiro ou um sentido transcendente a ser revelado. Por isso, pode ser conjecturado que, tendo em vista o argumento do filósofo francês, o pensamento heideggeriano seria a última expressão da necessidade de sentido do Ocidente. Heidegger seria aquilo que afirmara de Nietzsche: último metafísico. Heidegger seria o último metafísico pois em seu pensamento ainda haveria algum elo com o real em sua ambiguidade

\footnotetext{
${ }^{3}$ Em um cenário como esse falar em fake soa anacrônico, pois já se perdeu o lastro de verificação entre o que é e o que parece ser; entre o que é verdadeiro e falso. No fake ainda há apelo para a verificação da imagem, da informação e dos dados, algo que para Baudrillard não é mais resgatável.
} 
presente/ausente; material/imaterial; ôntica/ontológica. A tematização da era da técnica seria ainda uma tentativa de lembrança do real como desvelamento e, por isso, no âmago da verdade. Nesse escopo, a organização da história da filosofia empreendida por meio do rastreamento da noção de verdade seria uma tentativa de retomada da identidade ocidental e, simultaneamente, seu último suspiro:.Alétheia, veritas, certitudo, vontade de poder e pergunta pelo ser marcariam, assim, o esgotamento da relação com o real. Tem-se, então, a apoteose da simulação hiper-real.
A simulação parte, ao contrário da utopia, do princípio da equivalência, parte da negação radical do signo como valor, parte do signo como reversão e aniquilamento de toda referência. Enquanto a representação tenta absorver a simulação interpretando-a como falsa representação, a simulação envolve todo o edifício da representação como simulacro. Seriam estas as fases sucessivas da imagem:
1. Ela é o reflexo de uma realidade profunda
2. Ela mascara e deforma uma realidade profunda
3. Ela mascara a ausência de realidade profunda
4. Ela não tem relação com qualquer realidade: ela é o seu próprio simulacro puro (Baudrillard, 1991a, p. 13).

No trecho acima, ao se acompanhar certa linearidade de ruptura com o real, fica evidente a indicação de uma situação no mínimo peculiar: o simulacro não é o virtual que se opõe à realidade, o simulacro rompe relações com o real. Não se trata de descobrir a verdade por trás do simulacro e da simulação. Não há lembrança da realidade por meio da simulação, ela é tudo o que se apresenta, a simulação é total. $\mathrm{O}$ hiper-real é uma rede de signos marcados pela ausência de referência, de negatividade e solo transcendental. Não há metafísica no campo da hiper-realidade. Desta forma, a simulação cumpre uma função que o real jamais conseguiu ou conseguiria desempenhar, qual seja, a de se tornar total, sem sombras, sem restos, sem ambiguidades. No espaço do agora hiper-real, tudo simplesmente é. A era da simulação difere da era da técnica na medida em que, nesta, há vínculo com uma possibilidade de saída via resgate da ontologia do ser, questão filosófica originária. Aquela, por sua vez, rompe com qualquer lastro ontológico possível. Tanto é assim que a tentativa de pensar a "essência" da simulação já é também simulação. Tal lugar já é posto e aparelhado segundo uma organização simbólica do real. Mesmo que a tentativa de meditar a essência da simulação se pretenda, ela sim, verdadeira à revelia de todo o resto, já não se saiu de sua imersão numa rede de signos sem lastro. Toda tentativa dessa estirpe só pode continuar a se dar como simulação de realidade, exatamente porque tal exercício 
não rompe com o aparelhamento - para utilizar um termo de Heidegger - armado do hiper-real, mas é setor desta mesma armação simbólica. A busca contumaz do real na base dos simulacros é a reinserção na liquidez do campo significativo da hiperrealidade. Seria como mergulhar em um rio e querer bebê-lo ao ponto de apenas restar seu leito, impossível. No hiper-real uma vez que se está dentro, se está inteiramente dentro. Tal é o apontamento de Jean Baudrillard.

Na medida e que não há ontologia que dê a medida para o hiper-real, Baudrillard identifica nas revoluções tecnológicas dos meios de comunicação, da cibernética e da teoria de sistemas o solo de origem de sistemas de signos sem origem real. O processo de desenvolvimento tecnológico atrelado a essa transformação da comunicação cria o espaço da hiper-realidade por meio de si. Não custa observar o quanto o refinamento das tecnologias de informação e comunicação promovem esse tipo de situação ${ }^{4}$. Para o pensador francês, o aparelhamento ultra tecnológico promove a criação do campo simbólico da simulação. No entanto, a solução não seria desligar as máquinas e computadores ou parar de utilizar redes sociais. Não. A recente revolução tecnológica que sustenta o campo da simulação tem origem em ordens de simulacros mais antigas e que, paulatinamente se concretizaram possibilitando as seguintes. Pode se pensar a cópia artística - na escultura ou na pintura, por exemplo - como uma simulação que torna presente de algum modo o original e nesse sentido uma simulação fraca. Pode-se observar mais recentemente a produção industrial do século XIX. Esta produção, por sua vez, não remete a elemento primordial algum, uma vez que cada item produzido remete apenas à sua cópia irmã, também oriunda de linha de produção. No fim dessa esteira, o advento dos sistemas de comunicação e o desenvolvimento de um capitalismo tardio - no que tange ao seu ímpeto para a produção do campo simbólico e não apenas para a produção de itens materiais - geram o cenário de inserção em um campo para além do que foi a história até aqui. O campo histórico de signos sem origem para seus significados, ou seja, com significados hiper-reais. Sai de cena a realidade, entra em cena a hiper-realidade. Tal transição, como afirmada acima, sem possibilidade de retorno.

Conforme visto na primeira parte do texto, é possível - não sem muitas críticas delinear alguma narrativa para o Ocidente ao centralizar seu tema primordial, a verdade.

\footnotetext{
${ }^{4}$ Cabe também indicar que, nesse sentido, Baudrillard discorda de Heidegger em referência a afirmação
} de que "a essência da técnica não é técnica". 
Tal sentido para o tempo, com a hegemonia da simulação, se perdeu. Na medida que Baudrillard identifica uma ruptura com o tempo linear - do início, meio e fim -, uma vez que tal organização se dá segundo alguma remissão ao sentido do destino, o que se tem no contemporâneo é uma espécie de sem tempo no tempo simulado. Este, agora anestesiado, simultaneamente acelera e ralenta a vivência de seu ritmo. O tempo acelera na medida em que o processamento das informações se dá em tempo real no cálculo imediato de "acontecimentos" históricos - de forma um tanto quanto jocosa poderia se afirmar que a notícia chega antes do acontecimento e o replay antes do gol. Além disso, toda informação já chega desde uma demanda imediata pelo cômputo de seu significado, em um processamento que não permite que o tempo siga de fato algum ritmo específico. Tudo precisa ser, de pronto, entendido e processado. Por outro lado, o tempo ralenta. É assim na medida em que a densidade do fluxo de informações, mercadorias, mensagens etc. põe em dinâmica um circuito de quebra irresistível, produzindo uma massa populacional cuja capacidade de absorção destes mesmos elementos é nula. A inércia desse cenário é o elemento que impede a história de se dar segundo algum tempo específico, obliterando assim, a saída de seu jogo simulado.

Apesar disso, tal descolamento do tempo - oriunda do abandono do real - não significa o fim da história. Para Baudrillard, a história finda lá onde há a visualização do esgotamento de um caminho. Na simulação há um pôr-se para além do tempo que impede a visualização do tempo organizado segundo algum sentido. Tal inserção no "tempo" do mundo simulado faz inclusive esquecer e duvidar de que em algum momento houve tempo. Baudrillard chama tal fenômeno de efeito estereofônico. Segundo Horrocks: (2008, pp. $12-13)$

Efeito estereofônico se refere a tecnologias que alcançam, por exemplo, a perfeição da música reproduzida digitalmente. Essa simulação da música faz com que ela [música pré-digital] desapareça em seus efeitos especiais de ultrafidelidade. Tal processo, para Baudrillard, também aparece na microfísica e em todos os casos em que o espaço entre acontecimento e a reprodução, ou entre causa e efeito, se aproxima do ponto no qual este último, em sua pureza de reprodução (da música, de um acontecimento, de uma experiência) lança dúvidas sobre a existência da causa, tal como a música pré-digital.

O "tempo" do universo simulado faz esquecer e duvidar de que houve em algum momento tempo. Há modos mais prosaicos de exemplificação desse tipo de fenômeno, por exemplo, quando se produz batata industrialmente processada com sabor de carne ou se prefere o gosto artificial do morango ao morango de fato - quando muitas das 
vezes este jamais foi provado em seu gosto rústico. O universo das próteses simuladas do real se automatizam e se tornam independentes daquilo que simulam, não porque $o$ real está lá em algum lugar, mas justamente porque não está, por isso a simulação de sua permanência. Nesse campo semântico sem transcendência e a-metafísico, o diagnóstico fukuyamaniano de fim da história está derrubado. A história não chegou ao fim. Para chegar ao fim é preciso que ela seja vista, experimentada e testemunhada desde um compromisso com o sentido transcendente do real. No caso do Ocidente, um compromisso com a verdade. Em essência, para Baudrillard, fim da história é uma noção, de certa forma salutar, atrelada à ilusão vital de busca por algum sentido para a história. Essa busca insere na ilusão de um caminho, este sim, com início, meio e fim. A história do Ocidente poderia ter chegado ao fim, mas não se concretizou desta forma. $\mathrm{Na}$ simulação não se alcança tal estado de coisas, mas muito mais a noção de que a história foi neutralizada e de que o tempo parou. A luta contemporânea é pelo tempo, pela finitude, pelo fim, pela morte:

\footnotetext{
Existe algo oculto em nós: a nossa morte. Mas algo mais está escondido, aguardando-nos dentro de cada uma de nossas células: o esquecimento da morte. Nas nossas células, a nossa imortalidade repousa, esperando por nós. Costuma-se falar da luta da vida contra a morte, mas existe o perigo inverso. E precisamos lutar contra a possibilidade de não morrermos. Diante da menor hesitação na luta pela morte, os seres vivos se tornam idênticos uns aos outros e imortais (Baudrillard, 2001b, pp. 11-12).
}

Percebe-se um cenário curioso que isso traz: o fim do Ocidente abre um espaço de fim interminável onde a simulação é irrestrita e não há fim de fato. $\mathrm{O}$ mundo da simulação ilude toda tentativa de ruptura que demarque um vir a termo do fim, uma vez que na cadeia simbólica do hiper-real isso apenas produz um leve arrasto aerodinâmico. Complexo é tal drama contemporâneo de lutar pelo que não se conhece, lutar pela falha, pelo outro. Lutar pela morte é a luta pelo viver, pelo tempo, pelo real, por aquilo que não se sabe bem o que é, mas se acredita que algum dia foi. Para usar uma expressão baudrillardiana, o fim foi roubado da narrativa por meio de um crime perfeito (2001c, p.59). Roubaram o real sem que ninguém notasse. A imortalidade que se alcança por meio daí é aquela que reproduz o que já não é mais. Sem real, nutre-se da sua simulação gerando uma replicação infinita desse não lugar sob a aparência de que tudo está onde sempre esteve. Um convite ao faz de conta manso, que só deseja o que se pode ter e só tem o que se deseja. Nesse ralo sem fim do fim do Ocidente o sujeito humano não cessa de tragar. 


\section{A PANDEMIA COMO SIMULACRO GLOBAL E O TRIUNFO SOBRE A MORTE}

Ao se afirmar que a pandemia é um simulacro global, deve-se reforçar que simulação não é um sinônimo para falsidade. Um simulacro está para além de verdadeiro e falso, ele é um quantum de significado em meio a uma rede de significados sem real. A par disso, não se deve ler o título acima como uma voz de denúncia ao fake da pandemia mundial. Quem denuncia a pandemia como invenção não compreende o que é simulação. O vírus Sars-Cov-2 mata, a pandemia existe e todos correm risco de vida. Como será visto adiante, afirmar que a pandemia é um simulacro global significa dizer que o vírus de 2019 é um agente de hiper-realidade e desertificação do real a nível planetário. Cabe também ficar explícito que tal definição será tratada e desenvolvida sem nenhuma pretensão de predição. Como será o mundo pós Sars-Cov-2 e o "novo normal”, não se sabe. Não é o ponto elaborar uma espécie de futurologia, uma vez que o exercício do pensamento deve evitar seduções oraculares. O ponto é conseguir identificar a partir do que foi discutido até aqui, numa confrontação entre Heidegger e Baudrillard, como seria possível interpretar a pandemia que teve lugar em 2020.

Para que se inicie uma breve meditação acerca do acontecimento da pandemia sob a perspectiva da simulação, é necessário passar vista sobre algumas teses sobre o seu acontecimento. A primeira - e mais difundida delas - é a de que se trata de uma zoonose. Zoonoses são doenças que são transmitidas de animais para humanos, ou de humanos para os animais. Mais precisamente, são doenças ou infecções naturalmente transmissíveis entre animais vertebrados e seres humanos (OMS, 2020a). Tal tese investe na narrativa de que o vírus Sars-Cov-2 estaria presente em animais provavelmente morcegos - na cidade de Wuhan, na China, e por meio de um mercado popular teria entrado em contato com seres humanos e se expandiu, gerando a pandemia. Na medida em que um vírus se resume a uma informação genética, ele é algo que necessita da replicação de si mesmo em células já existentes para sobreviver. Tal replicação gera novas cópias do vírus, que estão em evolução contínua. Dentro desse fio condutor de análise, o vírus "encontrou" um jeito eficiente de se replicar de modo que prescindiu do morcego ao contaminar o novo hospedeiro humano. Fezes, saliva e até sopa de morcego surgem como possíveis causas para essa passagem ao humano. Uma tese como essa revela, talvez, um excesso de contato entre humanos e animais. Dentro da preocupação ambiental vigente, a pandemia talvez revele uma expansão desordenada 
da civilização, lá para onde ela deveria respeitar limites para o seu crescimento. $O$ vírus seria uma espécie de proteção da natureza frente ao expansionismo territorial e, quiçá, demográfico humano. Bem, parece uma tese consistente, mas existem outras teses que identificam tal "explicação oficial" como uma cortina de fumaça.

Alguns cientistas afirmam que o vírus foi criado em laboratório. Em entrevista à rádio Frequénce Médicale, o cientista francês Luc Montagnier, responsável pela descoberta do vírus HIV e ganhador do prêmio Nobel em 2008, afirma que o vírus foi fabricado em um laboratório em Wuhan (2020b). Trata-se do Instituto de Virologia de Wuhan (IVW), localizado no distrito de Jiangxia. Tal instituto se especializou no estudo de Zoonoses, especificamente entre morcegos e humanos, uma vez que tal fenômeno é comum na região onde o IVW se localiza. Justamente por isso, o IVW tem em seu repertório de análise quase 300 tipos de coronavírus transmissíveis entre morcegos e humanos (2020c). Segundo o cientista francês, o sequenciamento completo do código genético do Sars-Cov-2 indica que o mesmo possui uma parte "recortada" do vírus HIV e isso seria impossível de acontecer naturalmente. Tal fato indica que o coronavírus fora manipulado artificialmente antes de sua expansão pandêmica. Sua opinião é a de que, muito provavelmente, o IVW se ocupava da produção de uma vacina para o HIV, quando o vírus acidentalmente se propagou. A opinião segundo a qual o vírus foi produzido em laboratório também ganha força devido a um artigo chamado Unusual Features of the SARS-CoV-2 Genome Suggesting Sophisticated Laboratory Modification Rather Than Natural Evolution and Delineation of Its Probable Synthetic Route (2020d) publicado pela cientista chinesa Li-Meng Yan. Em tal artigo, a cientista e sua equipe de pesquisa identificam uma origem artificial do Sars-Cov-2 nos coronavírus ZC45 e ZXC21, estes sim, oriundos de morcegos. O sequenciamento genético do SarsCov-2 evidenciaria essa proveniência. Isso se reforça, segundo o artigo, pelo fato de os coronavírus ZC45 e ZXC21 serem de patente de laboratórios de pesquisa militares.

As posições acima, vindas de cientistas, tendem a receber créditos e evidenciariam a responsabilidade da China na propagação da pandemia ${ }^{5}$. No entanto, há

\footnotetext{
${ }^{5}$ Há interpretações mais selvagens acerca da responsabilidade chinesa. Uma delas afirma que a China produziu o vírus e o propagou para lucrar com a venda de vacinas; outra afirma que o vírus serve de agente de desestabilização econômica com o intuito de quebrar a economia mundial, elevando a China ao papel de única superpotência econômica no mundo; uma terceira associa o alastramento do vírus a um efeito colateral do desenvolvimento da internet $5 \mathrm{G}$ pela China. Na medida em que estas interpretações epistemologicamente alternativas surgem como que sem autoria, elas não foram citadas ao longo do texto.
} 
outras teses sobre a pandemia que implicam a participação de cientistas na disseminação de notícias falsas. A cientista citada acima, Li-Meng Yan, é associada à Rule of Law Society e à Rule of Law Foundation. Estas são instituições voltadas para uma espécie de libertação ideológica e política da China. Ambas são ligadas a Steve Bannon, assessor político estadunidense que foi assistente do presidente Donald Trump, estrategista da Casa Branca durante o seu governo e arquiteto de sua campanha política em 2016. Bannon, por sua vez, foi preso por fraude contra doadores de um fundo chamado $W e$ Build the Wall, que arrecadava recursos para ajudar Trump a levantar uma barreira na fronteira dos Estados Unidos com o México, uma das principais propostas de campanha do ex-presidente estadunidense. Bannon está ligado a movimentos de divulgação de notícias falsas com a finalidade de promoção de uma agenda política conservadora ao redor do mundo. Criou o grupo The Movement com a proposta de eleger líderes de extrema-direita a nível mundial. Sua influência se estende ao Brasil, como figura central para o modus operandi do ativismo digital da família Bolsonaro. Além disso, Bannon também esteve ligado ao escândalo da empresa Cambridge Analytica por conta da manipulação de dados pessoais gerados pelo uso das redes sociais. $\mathrm{O}$ alvo de tal ação seria a construção de notícias conspiratórias on demand para a finalidade política acima mencionada. A par disso, se torna complexa a simples aceitação da "neutralidade científica" no campo semântico da pandemia. Na verdade, desde Foucault - e seu conceito de poder-saber - a simples aceitação de um discurso científico desinteressado da malha de forças que o cercam parece utópico. Nesse escopo, o argumento de autoridade científico também aparece desde uma desconfiança de base, pois seu uso pode se dar sob diversas finalidades não científicas. Quem é capaz de garantir a total lisura de intenções dos cientistas mencionados? De onde surge o argumento final que chancela esse conhecimento como isento de erros? Luc Montagnier poderia se fazer valer de sua condição de prêmio Nobel para atingir objetivos políticos que porventura pudesse estar associado. Quem poderia negar?

No entanto, a tese acima, que desqualifica o posicionamento destes cientistas com base em supostos compromissos políticos, por sua vez, também recebe críticas. Steve Bannon, por exemplo, pode ser um cavaleiro da cruzada contra o stablishment globalista e por isso é perseguido pela grande mídia e vilanizado por suas ações castas. Quem poderia garantir o contrário? Bem, daí em diante tudo tende a se tornar difícil de 
analisar ao cair em um jogo interminável de reviravoltas conspiratórias. Portanto, a partir do breve relato de três teses - dentre infinitas teses ventiladas - sobre a pandemia e sua origem, nota-se o vai-e-vem sagaz de narrativas, que cria um cenário rocambolesco de viradas interpretativas que colocam em dúvida qualquer fala sobre o fato (fato?) da pandemia ${ }^{6}$. Dentro desse universo em espiral, entre o que é verdadeiro ou não, se exemplifica um traço central do mundo hiper-real:

Todas as hipóteses de manipulação são reversíveis num torniquete sem fim. É que a manipulação é uma causalidade flutuante onde positividade e negatividade se engendram e se recobrem, onde já não há ativo nem passivo. É pela paragem arbitrária desta causalidade rodopiante que pode ser salvo

E: um principio de realidade (Baudrillard, 2001, p.25).

\begin{abstract}
Um atentado à bomba na Itália é obra dos extremistas de esquerda ou provocação de extrema-direita, ou encenação centrista para desconsiderar todos os extremos terroristas e depreciar o seu poder vacilante? Tudo isto é verdadeiro ao mesmo tempo e a busca da prova e mesmo da objetividade dos fatos não para esta vertigem da interpretação. É que estamos numa lógica de simulação, que já nada tem a ver com a lógica dos fatos e uma ordem de razões. A simulação caracteriza-se por uma precessão do modelo, de todos os modelos sobre o mínimo fato. [...] Os fatos já não têm trajetória própria, nascem na interseção dos modelos, um único fato pode ser engendrado por todos os modelos ao mesmo tempo. Esta antecipação, esta precessão, este curto-circuito, esta confusão do fato com o seu modelo (acabam-se a falta de sentido, a polaridade dialética, a eletricidade negativa, a implosão dos polos antagônicos), é sempre ela que dá lugar a todas as interpretações possíveis, mesmo as mais contraditórias - todas verdadeiras, no sentido em que sua verdade é a de se trocarem, à semelhança dos modelos dos quais precedem, num ciclo generalizado (Baudrillard, 2001, p.26).
\end{abstract}

Os trechos acima são lapidares. É do campo da hiper-realidade o nivelamento dos discursos numa positividade sem fim. Sem real, o "fato" já não ocupa nenhum lugar relevante exatamente por conta dele já ser precedido por modelos de interpretação que mutuamente se nivelam e se anulam. Algum grau de "realidade" só se alcança pela simples paragem arbitrária da espiral de modelos interpretativos que se fazem presentes. O pensamento baudrillardiano nunca foi tão atual. A noção de hiper-realidade, se antes era parcamente visualizada por meio de exemplos locais e regionais, hoje se faz ver em cada rincão dos seis continentes pelo nivelamento dos povos empreendida pelo mesmo simulacro. A pandemia trouxe à tona um simulacro global inaugural, ela é a concretização às avessas do sonho ocidental por unidade. Antes do Sars-Cov-2 talvez

\footnotetext{
${ }^{6}$ Em uma coincidência de se gargalhar, toda interpretação da pandemia se assemelha ao comportamento de um vírus. São pequenas unidades de informação circulando no éter da noosfera, na busca pela hospedagem ideal. Todas potencialmente verdadeiras e falsas ao mesmo tempo. Sua longevidade vai depender do número de hospedeiros que alcançam.
} 
ainda fosse possível a ilusão de busca por exemplos periféricos que desviassem, ou que simulassem desviar, da grande rede simbólica que desertifica o real como marca do Ocidente em seu fim sem fim. O gasto cliché do sujeito-cansado-da-cidade-grande-quemigra-para-uma-pacata-e-remota-cidade-do-interior-em-busca-de-uma-vida-maissimples-e-lá-finda-por-encontrar-a-vida-de-verdade já não existe mais. Tais refúgios, já ilusórios e simulados antes da pandemia, foram detonados pelo vírus. Lá para onde se busca a "vida de verdade", de algum modo, se estará remetido ao real como deserto. Com a pandemia, a desertificação se totaliza. Se tal modo de desertificação do real não era radicalmente planetária, agora é. A pandemia é uma espécie de marco ou índice antropológico: é o fim do Ocidente como sem fim do Ocidente na sua proliferação planetária. A pandemia é o fato global que dá ensejo ao movimento em espiral da agonia interpretativa disso que não é nada além de simulação de real.

A sanha ocidental por unidade, pelo uno e pela verdade universal produziu seu reverso como esquecimento e o abandono do que se perseguia. Na medida em que se buscou o universal, o conjuntural se vingou, criando um espaço total - mas não universal - radicalmente sem origem. O Ocidente se consuma exatamente no ponto em que perde seus elementos norteadores: o real e a verdade. No vírus pandêmico, ele [Ocidente] se totaliza globalmente como simulação - como deserto do real. O vírus é o fim sem fim do Ocidente na sua concretização a nível global. A humanidade venceu o fim. Driblou a revelação e o apocalipse. Não há mais morte, diferença e alteridade. Com a pandemia ocasionada pelo Sars-Cov-2, somos todos um, planificados e unidimensionais. Como simples ilustração desse evento, o logotipo de divulgação para triagem teste para vacina de Oxford - talvez sem querer - corrobora tal tese.

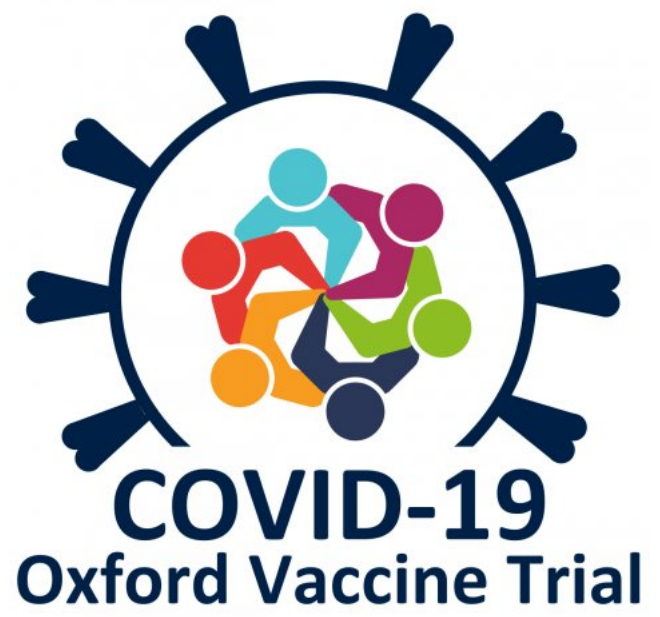




\section{CONCLUSÃO}

O presente texto buscou interpretar a pandemia que teve início no fim de 2019 a partir de confrontação entre os pensamentos de Martin Heidegger e Jean Baudrillard. De início, foi tematizada a paulatina transformação da noção de verdade por meio do diagnóstico heideggeriano da tradição ocidental como onto-teo-lógica. Para Heidegger, o que está em jogo aí é o problema do esquecimento da diferença ontológica. Dos antigos aos contemporâneos, ser e ente foram tomados como sinônimos, isso produziu um processo de paulatino esquecimento da questão ontológica como questão fundamental pela verdade. Ser "acontece" invariavelmente como tensão com o ente, como diferença radical. Em tal tensão, o que se abre ao ser-aí humano é o ser do ente, vinculado à medida de um mundo histórico possibilitado a partir dessa relação mesma da abertura do aí com o essenciar-se do ser. Tal essenciar-se se dá como recusa que retém o ser como radical diferença em relação àquilo que o ser mesmo, em diferindo, abre, isto é, um mundo. Por meio dessa ideia de diferença ontológica é possível pensar o processo constituidor de mundos históricos que possibilitam o mundo contemporâneo na sua especificidade de abandono dessa mesma questão ontológica. Tal tempo histórico Heidegger nomeia de era da técnica. Era da técnica é uma expressão para indicar em essência um esgotamento. Tal esgotamento é a consumação de um processo histórico de distanciamento do homem em relação ao vínculo com a clareira do ser. A isso Heidegger estabelece o nome de destino/envio do Ocidente. A era da técnica é o fim de um envio histórico do ser que se decidiu pelo abandono radical da diferença ontológica como fundamento infundado do aí. Portanto, Heidegger identifica na técnica o fim de uma trajetória histórica. $\mathrm{O}$ esgotamento epocal para Heidegger poderia ser superado na direção de uma retomada da experiência do ser, em um retorno salvador da ontologia.

Foi visto que, a partir de um direcionamento interpretativo específico do trabalho de Baudrillard, tal apontamento heideggeriano do fim do Ocidente abre o campo sem saída da simulação. Para o pensador francês não há mais testemunhas para a morte de Deus de Nietzsche, nem quem visualize o abandono da questão do ser de Heidegger. É assim na medida em que o real se perdeu e a linearidade histórica que, de algum modo, "amarrava" as concretizações históricas já não as une mais. O que se abre a partir daí é o espaço sem tempo e história da simulação da realidade: um campo hiperreal. Foi visto que, dentro do escopo do pensamento baudrillardiano, para tal niilismo 
hiper-real não há escapatória nem saídas possíveis uma vez que todas as ações que surgem neste campo surgem como simulação e trazem consigo a aniquilação de qualquer tipo de corte transcendental possível. Há, sim, a produção de uma rede simbólica na qual todo signo rompe relações com a consistência de sua validade mesma como significado. A saída desse cenário para sua superação perde justamente o elemento de corte que seria necessário para tal transição. Já não há Deus ex machina que altere o roteiro ou um sentido transcendente a ser revelado. Tal fato repercute em um descolamento radical do tempo e da transcendentalidade do campo da simulação. Onde isso acontece já não há mais temporalização, e onde não há mais temporalização tudo se torna deserto.

Apesar disso, antes da pandemia se poderia ter alguma ilusão quanto à possibilidade de refúgios e recantos isentos e protegidos da dinâmica de desertificação do real. Foi proposta, então, a interpretação segundo a qual o vírus Sars-Cov-2 é um agente de desertificação do real a nível global. Com o vírus e a pandemia, a desertificação como elemento ao qual não há possibilidade de não-lida se totaliza. $O$ mundo se fecha em uma redoma sem origem, cujo marco inaugural é pandemia. Se não havia simulacro planetário, agora há. A pandemia é uma espécie de marco ou índice antropológico: é o fim do Ocidente como sem fim do Ocidente na sua proliferação planetária. O "aqui" se torna o mesmo que "lá" e o presente é idêntico ao passado e ao futuro. Por mais que se movimente de um ponto a outro, já não há movimento algum, pois todas as coisas são versões sem real. Em algum lugar a eternidade se revela e, como verso da mesma moeda, por aqui, o ponteiro para de girar.

\section{Referências bibliográficas}

BAUDRILLARD, J. Ilusão vital. Rio de Janeiro: Civilização Brasileira, 2001 b. . Senhas. Rio de Janeiro: DIFEL, 2001c. . Simulacros e simulação. Lisboa: Relógio d'água, 2001a.

CABRAL, A. M. Niilismo e hierofania: um confronto a partir de Nietzsche, Heidegger e a tradição cristã. Volume 2: Heidegger e a polimorfia de Deus. Rio de Janeiro: Mauad X, 2015. 
| Dossiê | Pandemia e hiper-realidade: o fim sem fim do Ocidente em um confronto a partir de Heidegger e Baudrillard | Paulo Victor Rodrigues da Costa |

HEIDEGGER, M. Identidade e diferença. Petrópolis, RJ: Vozes, 2006. . Introdução à metafísica. 4 ed. Rio de Janeiro: Tempo Brasileiro, 1999.

. Heráclito. Rio de Janeiro: Relume Dumará, 1998.

. Nietzsche. 2 ed. Rio de Janeiro: Forense, 2014.

HORROCKS, J. Baudrillard e o milênio. Rio de Janeiro: Pazulin; Juiz de Fora: Ed. UFJF, 2008.

MONTAGNIER, L. (2020b) Entrevista [online]. https://istoe.com.br/NovocoronavIrus-foi-fabricado-em-laboratorio-chines-diz-descobridor-do-HIV. Acesso em 03 de janeiro de 2021.

OMS. (2020a). Zoonoses [online]. Disponível em: http://www.who.int/topics/zoonoses/en/. Acesso em 03 de janeiro 2021.

SUDWORTH, J. (2020c) Artigo jornalístico [online]. Disponível em: https://www.bbc.com/portuguese/internacional-55414443. Acesso em 03 de janeiro de 2021.

YAN, L-M. (2020d) Unusual Features of the SARS-CoV-2 Genome Suggesting Sophisticated Laboratory Modification Rather Than Natural Evolution and Delineation of Its Probable Synthetic Route. Artigo [online]. Disponível em: https://zenodo.org/record/4028830\#.X_IRVBZ7nIU. Acesso em 03 de janeiro de 2021.

Recebido em: 06/01/2021 | Aprovado em: 08/02/2021 